ISSN: 0213-2060

DOI: https://doi.org/10.14201/shhme2021391197213

\title{
LOS CONDES DE PRÉSARAS Y LA FUNDACIÓN DE SAN SALVADOR DE SOBRADO. EL INTENTO DE UNA PARENTELA MAGNATICIA POR RECUPERAR SU PREEMINENCIA EN GALLECIA
}

\author{
The Counts of Présaras and the Foundation of San Salvador de Sobrado. \\ The Attempt of a Magnatician Family for Recover their Pre-eminence in Gallecia
}

Gonzalo J. ESCUDERO MANZANO

Doctor en Historia y Arqueología - Universidad Complutense de Madrid. C/ General Ezponda, 14; 10003-Cáceres (España).C.e: gonzaesc@ucm.es.ORCID: orcid.org/0000-0001-7331-1043

Recibido: 2020/04/06

Revisado: 2020/10/30

Aceptado: 2020/11/09

RESUMEN: La sede episcopal de Santiago de Compostela fue uno de los primeros centros de la monarquía ovetense en Gallecia. Desde sus orígenes a comienzos de la novena centuria, estuvo vinculada directamente a una poderosa parentela local, los descendientes del comes Aloito. Durante varias décadas, los diversos reyes astur-leoneses promocionaron esta cátedra y se sirvieron de sus titulares para irradiar su autoridad sobre un territorio que comenzaba a integrarse en el regnum. Esta situación cambió a partir del segundo tercio del siglo x. La fundación del monasterio de Celanova por parte de otra poderosa familia del noroeste ibérico, los Gutiérrez, atrajo la atención de Ramiro II y quebró el monopolio ejercido por los obispos compostelanos. A lo largo de las siguientes páginas analizaré cuál fue la respuesta de los condes de Présaras, principales damnificados, para revertir esta situación y qué papel jugó San Salvador de Sobrado en esta nueva coyuntura.

Palabras clave: condes de Présaras; monasterio de Sobrado; obispado de Compostela; donaciones regias; promoción social.

ABSTRACT: The Episcopal see of Santiago de Compostela was one of the first centers of the Ovetense monarchy in Gallecia. Since its origins in the early ninth century, it was directly connected to a local powerful family, the descendants of comes Aloito. For many decades, the different Astur-Leonese kings promoted this seat and they served by their holders to give off their authority over a territory that commenced to been integrated into the regnum. This situation changed from the second third of tenth century. The foundation of the monastery of Celanova by another powerful family of the Iberian Northwest, the 
Gutiérrez, broke the monopoly exercised by Compostelanean bishops. Throughout the following pages, I will analyse what was the response of the Counts of Présaras, the main affected, for revert this situation and what role-played San Salvador de Sobrado in this new condition.

Keywords: Counts of Présaras; monastery of Sobrado; bishopric of Compostela; regal donations; social promotion.

SUMARIO: 0 Introducción. 1 La hegemonía de la sede jacobea en Gallecia (ca. 820-ca. 930). 2 La competitividad social y económica en Gallecia. 3 La reacción de los Menéndez: la fundación de San Salvador de Sobrado. 4 Familias, monasterios y pretendientes al regnum. 5 Conclusión. La inversión monástica como una forma de potenciar la atención regia y de conservar el patrimonio. 6 Referencias bibliográficas.

\section{INTRODUCCIÓN ${ }^{1}$}

Tras la conquista islámica del reino visigodo, el norte peninsular se transformó en un escenario en el que afloraron diversas unidades territoriales organizadas al margen de estructuras políticas supralocales ${ }^{2}$. Los únicos datos escritos de los que disponemos para estudiar la evolución de uno de estos grupos, el de los herederos de Pelayo, deben ser tomados con cautela a la hora de interpretar la información que nos ofrecen unas crónicas

1 Abreviaturas utilizadas: Ast = Cavero Domínguez, Gregoria y Martín López, Encarnación (eds.). Colección documental de la catedral de Astorga. Vol. I (646-1126). León: Centro de Estudios e Investigación San Isidoro, 2000; Cast = Rodríguez González, Ángel (ed.). El tumbo del monasterio de San Martín de Castañeda. León: Centro de Estudios e Investigación San Isidoro, 1973; Cel = Sáez Sánchez, Emilio y Sáez Sánchez, Carlos (eds.). Colección diplomática del monasterio de Celanova (842-1230). Alcalá de Henares: Universidad de Alcalá de Henares, 1996-2006, 3 vols.; CI = García Álvarez, Manuel R. (ed.). «El Cronicón Iriense. Estudio preliminar, edición crítica y notas históricas». En Memorial histórico español. Colección de documentos, opúsculos y antigüedades que publica la Real Academia de la Historia. Madrid: Real Academia de la Historia, 1963, pp. 101-121; HC = Falqué Rey, Emma (ed.). Historia Compostellana. Turnhout: Brepols, 1988; ID = Reglero de la Fuente, Carlos (ed.). El monasterio de San Isidro de Dueñas en la Edad Media. Un priorato cluniacense hispano (911-1478). Estudio y colección documental. León: Centro de Estudios e Investigación San Isidoro, 2005; Le = Sáez Sánchez, Emilio (ed.). Colección documental del archivo de la catedral de León (7751230). Vol. I (775-952). León: Centro de Estudios e Investigación San Isidoro, 1987; LM = Amaral, Luís C. (ed.). Livro de Mumadona. Cartulário do mosteiro de Guimarães. Edição crítica. Lisboa: Academiae Scientarum Olisiponensis, 2016; Lor = Nascimento, Aires A. y Fernández Catón, José M. a (eds.). Liber testamentorum coenobii laurbanensis. León: Centro de Estudios e Investigación San Isidoro, 2008; Sah = Mínguez Fernández, José M. ${ }^{a}$ (ed.). Colección diplomática del monasterio de Sahagún. Vol. I (siglos IX y X). León: Centro de Estudios e Investigación San Isidoro, 1976; SantA = Lucas Álvarez, Manuel (ed.). Tumbo A de la catedral de Santiago. Sada: Ediciós do Castro, 1998; Sob = Loscertales de Valdeavellano, Pilar (ed.). Tumbos del monasterio de Sobrado de los Monjes. Vol. I. Madrid: Archivo Histórico Nacional, 1976; Vega = Domínguez Sánchez, Santiago (ed.). Colección documental medieval de los monasterios de San Claudio de León, monasterios de Vega y San Pedro de las Dueñas. León: Centro de Estudios e Investigación San Isidoro, 2001.

2 Castellanos García, Santiago y Martín Viso, Iñaki. "The local articulation of central power in the North of the Iberian Peninsula (500-1000)». Early Medieval Europe, 2005, vol. 13, pp. 19-42. 
LOS CONDES DE PRÉSARAS Y LA FUNDACIÓN DE SAN SALVADOR DE SOBRADO. EL INTENTO

claramente viciadas por los presupuestos neogoticistas de finales de la novena centuria ${ }^{3}$. A pesar de ello, podemos interpretar la configuración de la primigenia formación política asturiana como una jefatura en la cual diversas facciones familiares aspiraron a hacerse con el caudillaje militar ${ }^{4}$.

En este contexto de fragmentación política y territorial, la vertiente cantábrica estuvo caracterizada por la coexistencia de parentelas heterogéneas de raigambre local cuyos líderes aprovecharon estas circunstancias para ascender social y económicamente 5 . No obstante, la evolución de estas comunidades fue divergente: en el Alto Ebro existió una mayor atomización condal hasta la unificación final por Fernán González en el siglo $\mathrm{x}^{6}$, entretanto que en Gallecia las élites locales fueron rápidamente incorporadas al regnum ${ }^{7}$. Como consecuencia, la implantación de la autoridad de los líderes ovetenses siguió dos directrices contrapuestas: en Castilla la monarquía apenas tuvo presencia ${ }^{8}$ mientras que el extremo occidental se constituyó como uno de los principales sostenes del poder regio?.

Sin embargo, como propuso Carlos Baliñas, la integración de las élites galaicas no fue siempre sosegada, sino que podemos distinguir dos etapas: una primera en la que habrían existido conflictos derivados del expansionismo asturiano y una segunda caracterizada por la colaboración con los líderes ovetenses ${ }^{10}$. Según Amancio Isla, una de estas fórmulas de cooperación habría consistido en la aceptación mutua entre los monarcas y estos líderes locales, a quienes los reyes reconocieron su preeminencia a cambio de atribuirse los éxitos conseguidos por sus iniciativas particulares ${ }^{11}$. Su integración en las estructuras del regnum permitió a estas aristocracias participar activamente en los

3 Isla Frez, Amancio. «Consideraciones sobre la monarquía astur». Hispania, 1995, vol. 55, pp. 151168; Dacosta Martínez, Arsenio. «Pelayo vive! Un arquetipo político en el horizonte ideológico del reino asturleonés». Espacio, Tiempo y Forma. Serie III, Historia Medieval, 1997, vol. 10, pp. 89-135; Escalona Monge, Julio. "Family memories. Inventing Alfonso I of Asturias». En Alfonso Antón, M. ${ }^{a}$ Isabel, Kennedy, Hugh y Escalona Monge, Julio (eds.). Building legitimacy. Political discourses and forms of legitimacy in Medieval societies. Leiden-Boston: Brill, 2004, pp. 223-262.

4 Mínguez Fernández, José M.a. «Regnum asturum. Orígenes y primera conformación». Intus-Legere Historia, 2014, vol. 8, pp. 51-69.

5 Martín Viso, Iñaki. «Colapso político y sociedades locales. El noroeste de la Península Ibérica (siglos VIII-IX)». Reti Medievali Rivista, 2016, vol. 17, passim.

6 Quirós Castillo, Juan Antonio y Santos Salazar, Igor. «Territorios sin ciudades y complejidad social. El Cantábrico oriental en la Alta Edad Media». En Sabaté i Curull, Flocel y Brufal Sucarrat, Jesús (eds.). La ciutat medieval i Arqueologia. VI Curs Internacional d'Arqueologia Medieval. Lleida: Pagès, 2014, pp. 157-162.

7 Sánchez Pardo, José Carlos. "Power and rural landscapes in Early Medieval Galicia (400-900 AD). Towards a re-incorporation of the Archaeology into the historical narrative». Early Medieval Europe, 2013, vol. 21, pp. 164-165.

8 Escalona Monge, Julio. "In the name of a distant King. Representing royal authority in the County of Castile, c. 900-1038». Early Medieval Europe, 2016, vol. 24, pp. 74-102.

9 Portass, Robert. «All quiet on the Western front? Royal politics in Galicia from c. 800 to c. 950». Early Medieval Europe, 2013, vol. 21, pp. 283-306.

10 Baliñas Pérez, Carlos. Do mito á realidade. A definición social e territorial de Galicia na Alta Idade Media (séculos VIII e IX). Santiago de Compostela: Fundación Universitaria de Cultura, 1992, passim.

11 Isla Frez, Amancio. "The aristocracy and the monarchy in Northwest Iberia between the Eighth and the Eleventh century». En D'Emilio, James (ed.). Culture and Society in Medieval Galicia: A Cultural Crossroads at the Edge of Europe. Leiden-Boston: Brill, 2015, pp. 255-258. 
LOS CONDES DE PRÉSARAS Y LA FUNDACIÓN DE SAN SALVADOR DE SOBRADO. EL INTENTO DE UNA PARENTELA MAGNATICIA POR RECUPERAR SU PREEMINENCIA EN GALLECIA GONZALO ESCUDERO MANZANO

acontecimientos políticos posicionándose con los distintos pretendientes al solio regio, una postura que fue paulatinamente consolidándose a lo largo de los siglos $\mathrm{Ix} \mathrm{y}^{12}$.

\section{La Hegemonía de LA SEDE JACOBEA en GALLECIA (CA. 820-CA. 930)}

La transición de la jefatura militar asturiana hacia una monarquía parece que coincidió con el comienzo de la integración y de la colaboración entre las élites galaicas y los líderes ovetenses. De acuerdo con Ermelindo Portela, uno de los primeros testimonios de este proceso es el conocido como documento de villa Ostulata ${ }^{13}$. Bajo mi punto de vista, este diploma podría tener una lectura mucho más compleja. En la escritura aparecen dos personajes con un cargo público: el comes Aloito y el episcopus Quindulfo. Del primero sabemos que estaba actuando en este espacio per ordinationem domni Adefonsi principis y - como señaló Margarita Torres- habría sido el miembro inicial de una parentela colaboradora con la monarquía en Gallecia y el ascendiente de varios obispos compostelanos ${ }^{14}$. Respecto al segundo, parece que su función fue sancionar este consilium inter se agitantes. Si admitimos que se trató del mismo individuo que confirmó el Testamentum Regis Adefonsi ${ }^{15}$, seguramente actuó como un delegado de la autoridad regia en este espacio $^{16}$.

Asimismo, los confirmantes del documento de villa Ostulata están divididos en dos secciones según su procedencia geográfica: algunos vinieron de Asturias, otros de Iria. En el primer grupo encontramos a Teodemiro, tal vez el mismo personaje que aparece en el susodicho Testamentum Regis Adefonsi, acaso quien — como sabemos gracias a su lápida funeraria ${ }^{17}$ — ostentara la dignidad iriense desde la recién creada sede episcopal y, por lo tanto, el responsable según la Historia Compostelana y el Cronicón Iriense del hallazgo de las reliquias de Santiago ${ }^{18}$.

De esta forma, quizás el concilium celebrado en Vilouchada fuera el germen de la fundación de la cátedra jacobea. Si bien los orígenes de esta sede son difíciles de precisar, el patrocinio directo por parte de la monarquía sobre este centro tuvo por objetivo

12 Branco, M. a João. «Portugal no reino de León. Etapas de uma relação (866-1179)». En El reino de León en la Alta Edad Media. León: Centro de Estudios e Investigación San Isidoro, 1993, vol. IV, pp. 541-558.

13 Portela Silva, Ermelindo. «El rey y los obispos. Poderes locales en el espacio galaico durante el periodo astur». En Fernández Conde, Francisco Javier y García de Castro Valdés, César (coords.). Symposium Internacional Poder y Simbología en Europa, siglos VIII-X. Actas del Symposium Internacional convocado en Oviedo, 22-27 de septiembre del 2008. Oviedo: Trea, 2009, pp. 219-220. Para el documento, vid. Sob, doc. 43.

14 Torres Sevilla-Quiñones de León, Margarita. Linajes nobiliarios en León y Castilla (siglos IX-XIII). Valladolid: Junta de Castilla y León, 1999, pp. 312-319.

15 Floriano Cumbreño, Antonio C. (ed.). Diplomática española del periodo astur. Vol. I (desde Pelayo a Ordoño I). Diputación Provincial de Oviedo, Oviedo: Instituto de Estudios Asturianos, 1949, doc. 24.

16 Baliñas Pérez, Carlos. Gallegos del año mil. La Coruña: Fundación Pedro Barrié de la Maza, 1998, pp. 192-200.

17 Núñez Rodríguez, Manuel. «Inscripciones de la Galicia altomedieval». Revista de Guimarães, 1979, vol. 89 , n. 36 .

$18 H C$, II $\$ 1 ; C I, \$ 4$. 
LOS CONDES DE PRÉSARAS Y LA FUNDACIÓN DE SAN SALVADOR DE SOBRADO. EL INTENTO

— como señaló Carlos Baliñas - constituir una especie de illa de autoridade desde la cual los gobernantes asturianos proyectaron su poder sobre un espacio que estaban comenzando a integrar bajo su órbita ${ }^{19}$, legitimado además con la cobertura ideológica de la protección apostólica sobre la monarquía ovetense ${ }^{20}$. La proximidad de villa Ostulata a Compostela y la simultaneidad entre la emisión de este documento y la creación del nuevo asiento episcopal en las primeras décadas de la novena centuria - aceptando los cálculos de Fernando López Alsina ${ }^{21}$ — pudieran corroborar esta posibilidad.

A partir de entonces, floreció un núcleo asociado directamente a la autoridad regia dirigido por obispos seleccionados entre los partidarios políticos de los reyes astur-leone$\mathrm{ses}^{22}$. En un primer momento, la cátedra jacobea fue la gran beneficiada por Alfonso III, sobre todo con posesiones confiscadas a distintos rebeldes ${ }^{23}$. Esta política fue continuada por sus vástagos: la Iglesia compostelana recibió cuantiosos objetos muebles y explotaciones fundiarias de Ordońo $\mathrm{II}^{24}$, mientras que Fruela II cedió a este centro numerosas propiedades territoriales y el comisso de Montanos $^{25}$.

El crecimiento material de esta sede gracias a la promoción directa por la monarquía tuvo también su reflejo en los titulares episcopales, pues los sucesores de Teodomiro al frente de esta cátedra estuvieron estrechamente ligados a los líderes ovetenses. Según el Cronicón Iriense, Sisnando procedía de Liébana y había sido capellanus de Alfonso III ${ }^{26}$. Su obtención de la mitra parece que se produjo per concilium electus et ordinatus por el propio rey ${ }^{27}$, aproximadamente en el año 883 , aparece integrado junto con el resto de prelados en la Notitia episcoporum cum sedibus suis contenida en la Crónica Albeldense ${ }^{28}$. Asimismo, la Historia Compostelana señala que Gundesindo era hijo del comes Aloito $^{29}$, es decir, provendría de la familia encargada de incorporar este territorio a la órbita ovetense.

Las tensiones por hacerse con el solio regio también parece que repercutieron en Compostela. Tras la muerte de Ordoño II, su hermano Fruela II confirmó al frente de

19 Balińas Pérez, Carlos. «Igrexa e política na Galicia do periodo asturiano (718-910)». Cuadernos de Estudios Gallegos, 1986, vol. 36, pp. 77-79.

20 López Alsina, Fernando. "Cabeza de oro refulgente de España”. Los orígenes del patrocinio jacobeo sobre el reino astur». En Ruiz de la Peńa, Juan Ignacio (ed.). Las peregrinaciones a Santiago de Compostela y San Salvador de Oviedo en la Edad Media. Actas del Congreso Internacional celebrado en Oviedo del 3 al 7 de diciembre de 1990. Oviedo: Principado de Asturias, 1993, pp. 95-107.

21 López Alsina, Fernando. La ciudad de Santiago de Compostela en la Alta Edad Media. Santiago de Compostela: Universidade de Santiago de Compostela, 1992, pp. 113-118.

22 Barreiro Somoza, José. El señorio de la Iglesia de Santiago de Compostela (siglos IX-XIII). La Coruña: Diputación Provincial de La Coruña, 1987, pp. 79-93; Balińas Pérez, Gallegos del año mil, pp. 189-192.

23 SantA, docs. 12, 13 y 15.

24 SantA, docs. 21, 22, 23, 24, 25, 27, 29, 32 y 33. Sobre la relación entre los bienes de prestigio y el fortalecimiento de redes clientelares, vid. Earle, Timothy K. How chiefs come to power. The political economy in Prehistory. Stanford: Stanford University Press, 1997, pp. 154-155.

25 SantA, docs. 36, 37 y 38.

26 CI, $\$ 6$.

27 SantA, doc. 8 .

28 «Crónica Albeldense», $\$ 12$. En Gil Fernández, Juan, Moralejo Álvarez, José Luis y Ruiz de la Peña, José Ignacio (eds.). Crónicas asturianas. Crónica de Alfonso III (Rotense y "a Sebastián»). Crónica Albeldense (y "Profética»). Oviedo: Universidad de Oviedo, 1985.

$29 H C$, I, 2, $\$ 4$. 
LOS CONDES DE PRÉSARAS Y LA FUNDACIÓN DE SAN SALVADOR DE SOBRADO. EL INTENTO DE UNA PARENTELA MAGNATICIA POR RECUPERAR SU PREEMINENCIA EN GALLECIA GONZALO ESCUDERO MANZANO

esta sede a Hermegildo ${ }^{30}$, quien a su vez se convirtió en el principal apoyo episcopal del nuevo monarca ${ }^{31}$. Entretanto, la constitución de la cátedra jacobea como el principal sostén de la autoridad regia en Gallecia lo podemos apreciar gracias a la ya referida cesión del comisso de Montanos. De acuerdo con Âlvaro Carvajal, debemos entender este tipo de propiedades como la delegación de un dominio a un colaborador de la monarquía, de tal forma que los reyes tenían la potestad de disponer de los comissa y de redistribuirlos libremente ${ }^{32}$. Sabemos que Montaos había pertenecido previamente a Sigeredo Égicaz ${ }^{33}$, acaso un partidario de Ordońo II que se vio desplazado por un agente simpatizante de Fruela II.

Con la nueva fragmentación territorial consecuente de los conflictos entre los nietos de Alfonso III por obtener el regnum ${ }^{34}$, Sancho Ordóñez continuó promocionando a la sede apostólica. Su titular, Hermegildo, recibió la confirmación de varias posesiones anteriores y adquirió otras nuevas, incluyendo los comissa de Monte Sacro y Ameás secundum illas obtinerunt Lucidus Vimarani et Nunus Gutherrizi ${ }^{35}$. De nuevo parece que nos encontramos ante una política de reordenación de las fuerzas afines a los distintos pretendientes al solio.

Finalmente, a partir del segundo tercio del siglo x, la victoria de Ramiro II sobre el resto de aspirantes trajo un período de estabilidad durante dos décadas ${ }^{36}$. Como ha expuesto Carlos de Ayala, este monarca se sirvió de los obispos para llevar a cabo una centralización política ${ }^{37}$. Sin embargo, en Gallecia, podemos notar un cambio en sus donaciones. A pesar de que al comienzo de su reinado confirmó a la cátedra jacobea la posesión de sus propiedades y le otorgó el comissum Pistomarcos ab integro secundum illud obtinuit Lucidus Vimarani ${ }^{38}$, la atención regia se desplazó hacia el sur y las concesiones

30 Per huius nostrae preceptionis serenissimam iussionem, hordinamus vobis [Hermegildo episcopo] possesam et imperandam sedem Iriensem, quae est coniuncta loco patroni sancti Iacobi apostoli (SantA, doc. 37). Para el significado de la iussio regis, cf. Mínguez Fernández, José M.a. «Pervivencia y transformaciones de la concepción y práctica del poder en el reino de León (siglos x y xI)». Studia Historica. Historia Medieval, vol. 25, 2007, pp. 16-29.

31 Ayala Martínez, Carlos de. Sacerdocio y reino en la España altomedieval. Iglesia y poder político en el occidente peninsular, siglos VII-XII. Madrid: Sílex, 2008, pp. 184-187.

32 Carvajal Castro, Álvaro. Bajo la máscara del regnum. La monarquía asturleonesa en León (8541037). Madrid: Consejo Superior de Investigaciones Científicas, 2017, pp. 161-162.

33 SantA, doc. 38.

34 Viguera Molins, M. ${ }^{a}$ Jesús, Corriente Córdoba, Federico y Lacarra de Miguel, José M. ${ }^{a}$ (eds.). Crónica del califa 'Abderramān III an-Nāsir entre los años 912 y 942 (al-Muqtabis V). Zaragoza: Anubar, 1981, $\$ 233$.

35 SantA, docs. 50 y 51.

36 Rodríguez Fernández, Justiniano. «La monarquía leonesa. De García I a Vermudo III». En El reino de León en la Alta Edad Media. Vol. III. León: Centro de Estudios e Investigación San Isidoro, 1995, pp. 276-289.

37 Ayala Martínez, Sacerdocio y reino en la España altomedieval, pp. 200-205.

38 SantA, docs. 39 y 40. Lucídio Vimaranes fue un estrecho colaborador de Ordońo II (Branco, «Portugal no reino de León», p. 557), sin embargo, tampoco hay que descartar que esta reordenación territorial respondiera a una confiscación a un partidario de Alfonso IV en Gallecia. 
fundiarias pivotaron en torno a los monasterios de Celanova ${ }^{39}$, Guimarães ${ }^{40}$ y Lorvão $^{41}$, seguramente como agradecimiento a las parentelas locales que sustentaron su ascenso al frente del regnum $^{42}$. Como consecuencia, el principal centro de la monarquía en Gallecia, Santiago de Compostela, perdió protagonismo y se vio relegado a una posición secundaria, como podemos apreciar en el Gráfico 1:

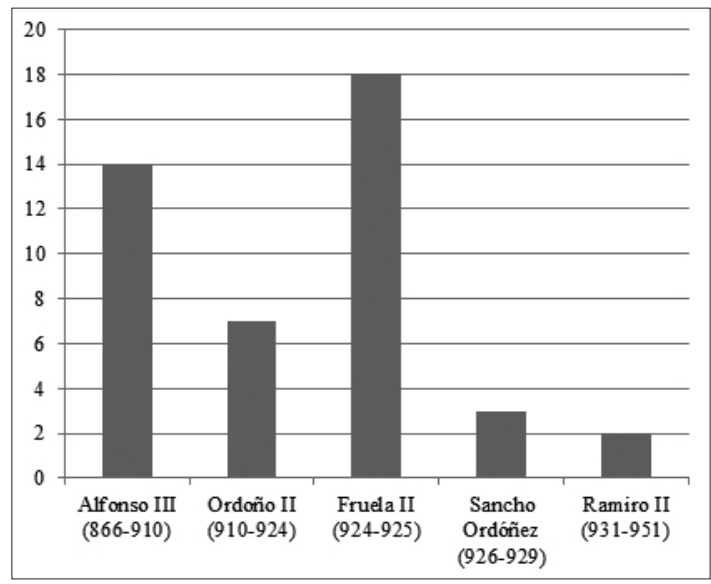

GrÁfico 1: Concesiones totales a Compostela por parte de la monarquía en cada uno de los actos de donación. Fuente: SantA, docs. 12, 13, 15, 21, 22, 23, 24, 25, 27, 29, 32, 33, 36, 37, 38, 39, 40, 50 y 51.

\section{LA COMPETITIVIDAD SOCIAL Y ECONÓMICA EN GALLECIA}

Como hemos estado viendo, hasta el segundo tercio del siglo x, la sede jacobea monopolizó las concesiones regias en Gallecia y sus obispos fueron valiosas piezas al servicio de la monarquía. ¿Qué pudo suceder para que, repentinamente, el principal centro del noroeste peninsular sobre el que se apoyaban los distintos pretendientes al solio regio perdiera su posición preeminente? Para solventar esta incógnita, comenzaré por rastrear quiénes fueron favorecidos por Ramiro II, para lo cual he desglosado su política del don en el Gráfico 2:

39 Cel, docs. 47,69 y 85 .

40 LM, docs. 10 y 49.

41 Lor, doc. 37.

42 Sáez Sánchez, Emilio. "Ramiro II, rey de "Portugal”". Revista Portuguesa de História, 1947, vol. 3, pp. 283-287. 


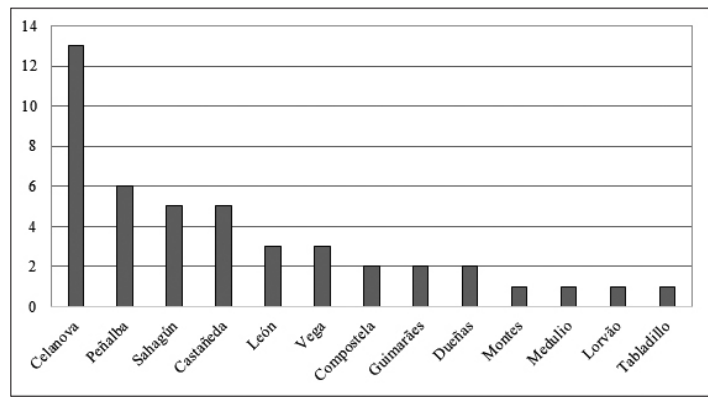

Gráfico 2: Donaciones de Ramiro II a instituciones eclesiásticas dentro de cada uno de los diplomas emitidos. Fuente: Ast, docs. 45, 49, 55, 64 y 65; Cast, doc. 2; Cel, docs. 47, 69 y 85; ID, docs. 7 y 8 ; Le, doc. 149; LM, docs. 10 y 49; Lor, doc. 37; Sah, doc. 93; SantA, docs. 39 y 40; Vega, doc. 2.

Como se puede apreciar, el principal beneficiario de Ramiro II fue el monasterio de Celanova. Fundado a lo largo del año $937^{43}$, su promotor fue una poderosa parentela galaica descendiente de los comites Gatón y Hermenegildo ${ }^{44}$. Esta institución no solo fue capaz de desbancar a la potente sede compostelana, sino que también fue el único centro galaico que recibió propiedades por parte de la monarquía, mientras que, en León, en El Bierzo y al sur del río Limia existió un mayor reparto de las donaciones regias entre diversos centros eclesiásticos. Por consiguiente, parece que fue la aparición de este cenobio el causante de la ruptura del statu quo en el extremo noroccidental hispánico.

A pesar de que contamos con el trabajo clásico de Emilio Sáez para conocer a fondo el origen de esta familia ${ }^{45}$, creo conveniente hacer un repaso general de sus miembros más destacados para poder contextualizar mejor la competitividad entre los distintos grupos aristocráticos. Tras el colapso del reino visigodo, el norte peninsular se convirtió en un escenario de nuevas oportunidades en el que diversos líderes locales tuvieron la capacidad suficiente como para llevar a cabo iniciativas particulares de expansión ${ }^{46}$. Gatón y Hermenegildo fueron dos de estos ejemplos, al igual que el comes Aloito que aparece en el documento de villa Ostulata ${ }^{47}$. Sabemos que el primero dirigió al populus de Bergido pro Astorica populare ${ }^{48}$, mientras que el Chronicon Laurbanense nos indica que prendita est

43 Tomo como terminus post quem septiembre del 936, cuando Froila Gutiérrez cedió ac germanis mei, domni Rudesindi episcopi, construatur ibi templum in nomine domini mei Salvatoris, in cuius nomine votum istum dedicavi ut sub imperio eiusdem pontificis almi hedificent ibi monasterium et congregetur ibi fratrum congregatio Deo (Cel, doc. 53); por otra parte, la datación ante quem la marco en febrero del 938, con la primera donación testimoniada a este centro (Cel, doc. 57).

44 Pallares Méndez, M. a Carmen. Ilduara, una aristócrata del siglo X. Sada: Ediciós do Castro, 1998.

45 Sáez Sánchez, Emilio. "Los ascendientes de san Rosendo. Notas para el estudio de la monarquía astur-leonesa durante los siglos IX y X». Hispania, 1948, vol. 8, pp. 5-136.

46 Isla Frez, Amancio. Ejército, sociedad y politica en la Peninsula Ibérica entre los siglos VII y XI. Madrid: Ministerio de Defensa, Consejo Superior de Investigaciones Científicas, 2010, pp. 143-150.

47 Balińas Pérez, Gallegos del año mil, pp. 97-103.

48 Ast, doc. 5. Para una mejor interpretación de este acontecimiento, vid. Carvajal Castro, Álvaro y Martín Viso, Ińaki. "Historias regionales de la repoblación. Los reyes asturleoneses y las "políticas de la tierra” en el oeste de la Meseta del Duero». En Díaz Martínez, Pablo C., Luis Corral, Fernando y Martín Viso, 
LOS CONDES DE PRÉSARAS Y LA FUNDACIÓN DE SAN SALVADOR DE SOBRADO. EL INTENTO

Conimbria ad Ermegildo comite ${ }^{49}$. Todos estos individuos crearon complejas redes clientelares y patrimoniales con el fin de afianzar su posición sociopolítica y aumentar sus explotaciones fundiarias ${ }^{50}$, una dinámica que desembocaría tras la muerte de Ramiro II en un enfrentamiento directo entre las diversas parentelas ${ }^{51}$, fundamentalmente las representadas por los obispos Sisnando Menéndez y Rosendo Gutiérrez ${ }^{52}$.

La inversión de los descendientes de los comites Gatón y Hermenegildo con la fundación de un monasterio, San Salvador de Celanova, sirvió para atraer el interés de Ramiro II a la hora de utilizar un nuevo centro desde el cual proyectar su autoridad en Gallecia, una labor que hasta el momento había desempeñado Santiago de Compostela. La consecuencia directa fue que los herederos del comes Aloito — quienes habían monopolizado la dignidad iriense y la atención de la monarquía - se vieron relegados a un plano secundario en la política del regnum. De esta forma, durante el segundo tercio del siglo x se produjo la ruptura del statu quo que había caracterizado a la sociedad galaica desde hacía más de un siglo.

\section{La reacción de los Menéndez: la fundación de San Salvador de Sobrado}

A pesar de que la sede iriense y los descendientes del comes Aloito habían sido desplazados en el terreno económico a una posición secundaria, ello no es indicativo de la pérdida de su preeminencia social y política. Durante el reinado de Ramiro II, fueron propietarios del condado de Présaras y, tanto Hermenegildo Aloítez como su hijo Sisnando Menéndez, estuvieron integrados en la corte con el título de maiordomus; igualmente, este último fue nombrado obispo de Compostela ${ }^{53}$. La historiografía ha explicado su obtención de la mitra como agradecimiento del servicio prestado por su familia a la monarquía ${ }^{54}$, mas, ¿por qué se trata del único caso conocido de un abandono de un cargo cortesano por uno episcopal? ¿Por qué fue elegido Sisnando y no otro miembro de esta familia? ¿Qué particularidad esconde esta excepcionalidad?

Ińaki (coords.). El historiador y la sociedad. Homenaje al profesor José Ma Minguez. Salamanca: Universidad de Salamanca, 2013, pp. $42-43$.

49 "Chronicon Laurbanense». En Portugaliae Monumenta Historica. Scriptores. Lisboa Academiae Scientarum Olisiponensis: 1856, vol. I, p. 20.

50 Portela Silva, Ermelindo y Pallares Méndez, M. ${ }^{a}$ Carmen. «Elementos para el análisis de la aristocracia altomedieval de Galicia. Parentesco y patrimonio». Studia Historica. Historia Medieval, 1987, vol. 5, pp. 17-32.

51 Baliñas Pérez, Carlos. Defensores e traditores. Un modelo de relación entre poder monárquico e oligarquia na Galicia altomedieval (718-1037). Santiago de Compostela: Xunta de Galicia, 1988, pp. 64-72.

52 Portela Silva, «El rey y los obispos», pp. 223-225.

53 García Álvarez, Manuel R. «Sisnando Menéndez, mayordomo real y obispo de Santiago». Compostellanum, 1968, vol. 13, pp. 199-239.

54 López Ferreiro, Antonio. Historia de la Santa A. M. Iglesia de Santiago de Compostela. Vol. II. Santiago de Compostela: Seminario Conciliar Central, 1899, pp. 317-319; Palomeque Torres, Antonio. Episcopologio de las sedes del Reino de León. León: Centro de Estudios e Investigación San Isidoro, 1966, pp. 317-318; Ayala Martínez, Sacerdocio y reino en la España altomedieval, p. 206. 
LOS CONDES DE PRÉSARAS Y LA FUNDACIÓN DE SAN SALVADOR DE SOBRADO. EL INTENTO DE UNA PARENTELA MAGNATICIA POR RECUPERAR SU PREEMINENCIA EN GALLECIA GONZALO ESCUDERO MANZANO

$\mathrm{Al}$ igual que sus antagonistas, los Menéndez estuvieron estrechamente vinculados a un monasterio: San Salvador de Sobrado. A finales de la década de los setenta del siglo pasado - dentro de las corrientes historiográficas que interpretaban los movimientos de «repoblación» desde la óptica pidaliana de organización e integración de unas comunidades rurales administrativamente autónomas ${ }^{55}$ - M. ${ }^{a}$ del Carmen Pallares contextualizó la construcción de este cenobio en «el marco general de las fundaciones monásticas que acompañaron al proceso colonizador subsiguiente a la Reconquista y que tiene sus antecedentes en la época visigoda ${ }^{56}$.

Sin embargo, parece que se trató de un proceso más complejo. La fundación de un monasterio fue utilizada para establecer un lugar central que perpetuara la memoria de una parentela, que fijara y aumentara el patrimonio familiar y que permitiera a algún miembro su entrada en la carrera eclesiástica ${ }^{57}$. Este es el contexto en el cual hemos de comprender la instauración de San Salvador de Sobrado, es decir, fue una reacción de los condes de Présaras ante el desplazamiento en la política de donaciones al que se vieron sometidos por parte de Ramiro II y un intento de evitar la dispersión fundiaria y de conservar su poder local.

Gracias a varios diplomas procedentes de este monasterio, sabemos que fue una empresa personal de Sisnando ${ }^{58}$, no de sus padres, probablemente motivado por actuaciones similares de otras aristocracias coetáneas y con la finalidad de disponer de un baluarte sobre el que asentar su dominio ${ }^{59}$. A pesar de que Pallares interpretó sendas donaciones de Hermenegildo y de Paterna a Sobrado (mayo y octubre del año 951) ${ }^{60}$ como las cartas fundacionales de este cenobio ${ }^{61}$, bajo mi juicio, estas concesiones territoriales solo podrían haber sido realizadas una vez que esta institución estuviera en funcionamiento y, por lo tanto, ya edificado o - como señaló Antonio Palomeque ${ }^{62}$ — en una fase terminal de construcción.

Todo apunta a que esta inversión le permitió alcanzar la dignidad iriense, pues sabemos que durante la Alta Edad Media la fundación de un monasterio sirvió para que su promotor fuera reconocido con el título episcopal ${ }^{63}$. A partir de entonces, Celanova per-

55 García de Cortázar, José Ángel. «Del Cantábrico al Duero». En García de Cortázar, José Ángel et al. (eds.). Organización social del espacio en la España medieval. La Corona de Castilla en los siglos VIII a XV. Barcelona: Ariel, 1985, pp. 43-83; Mínguez Fernández, José M. ${ }^{a}$. «Ruptura social e implantación del feudalismo en el noroeste peninsular (siglos viII-X)». Studia Historica. Historia Medieval, 1985, vol. 3, pp. 7-32.

56 Pallares Méndez, M. ${ }^{a}$ Carmen. El monasterio de Sobrado. Un ejemplo de protagonismo monástico en la Galicia medieval. La Coruña: Diputación Provincial de La Coruña, 1979, pp. 71-76.

57 Isla Frez, "The aristocracy and the monarchy in Northwest Iberia», pp. 269-273.

58 Vobis patri domno Sisnando episcopo, qui hunc locum sub domini virtute edificastis (Sob, doc. 106); monasterium fundatum sub regimine et tuitione monachorum patri domno Sisnando episcopo (Sob, doc. 8).

59 Balińas Pérez, Gallegos del año mil, pp. 220-221.

60 Sob, docs. 1 y 3.

61 Pallares Méndez, El monasterio de Sobrado, p. 71.

62 Palomeque Torres, Episcopologio de las sedes del reino de León, p. 319.

63 Escudero Manzano, Gonzalo J. «Los escenarios episcopales en el norte hispánico entre la caída del reino visigodo y la configuración del poder leonés (siglos viII-X)». En Díaz-Plaza Casal, Adrián, Escudero Manzano, Gonzalo J. y Villarroel González, Óscar (coords.). Caida y ascenso de las estructuras de poder en la Alta Edad Media. Madrid: La Ergástula, 2020, pp. 79-91. 
LOS CONDES DE PRÉSARAS Y LA FUNDACIÓN DE SAN SALVADOR DE SOBRADO. EL INTENTO

dió su monopolio en Gallecia y, después de casi dos décadas, la sede jacobea —vinculada a la parentela del comes Aloito— - volvió a contar con donaciones regias ${ }^{64}$. No obstante, ni alcanzó las altas cuotas de épocas anteriores ni consiguió desbancar a sus rivales ${ }^{65}$.

\section{FAMILIAS, MONASTERIOS Y PRETENDIENTES AL REGNUM}

Este ligero reequilibrio social y económico coincidió con el debilitamiento de la autoridad leonesa durante la segunda mitad del siglo $\mathrm{x}^{66}$. En Gallecia, las tensiones ya eran latentes desde el gobierno de Ordoño III, quien — según Sampiro— asentó su autoridad a través de una intervención armada ${ }^{67}$. No obstante, no parece que sus opositores fueran los Gutiérrez ni los Menéndez, puesto que sendas parentelas recibieron donaciones de este rey ${ }^{68}$. Su muerte vino acompañada de nuevos conflictos y los obispos Rosendo y Sisnando se posicionaron en facciones opuestas: el primero con Sancho I y el segundo con Ordońo IV.

Esta ruptura entre las aristocracias galaicas ha sido reducida, fundamentalmente, a un enfrentamiento personal entre las distintas parentelas que repercutió en el sostenimiento de distintos aspirantes al regnum ${ }^{69}$. Sin embargo, bajo mi punto de vista, el aval de los Menéndez a un nuevo monarca quizás fue la exteriorización de su descontento con la política de Ramiro II y de sus hijos y la búsqueda de un pretendiente que pudiera recompensar su servicio y les permitiera recobrar el rol predominante que habían ejercido en el pasado. La apuesta de Sisnando resultó efectiva y, después de una década, la cátedra que dirigía volvió a contar con el favor regio ${ }^{70}$. Asimismo, en agradecimiento por su victoria super inimicus, Ordoño IV confirmó la construcción del monasterio de Sobrado y la posesión del comissum de Présaras ${ }^{71}$. Gracias a este documento podemos comprobar que el apoyo que recibió el pretendiente al solio regio por parte de los Menéndez en contra de otras aristocracias locales debió de ser esencial para la consolidación de su autoridad en Gallecia.

No obstante, la definitiva victoria de Sancho I sobre Ordoño IV truncó las aspiraciones de esta parentela para recuperar su protagonismo político y —según la Historia Compostelana, el Cronicón Iriense y la Vida de San Rosendo - parece que Sisnando habría

64 SantA, docs. 43, 44, 45 y 49.

65 Ordońo III continuó apoyándose en Rosendo de Celanova para asentar su poder en el noroeste (Cel, docs. 90 y 110).

${ }_{66}$ Mínguez Fernández, José M.a. La España de los siglos VI al XIII. Guerra, expansión y transformaciones. En busca de una frágil unidad. San Sebastián: Nerea, 2004, pp. 177-182.

67 Ipse quidem rex Ordonius magno exercitu agregato Galleciam edomuit (Pérez de Urbel, Justo (ed.). Crónica de Sampiro. Versión Silense. Madrid: Consejo Superior de Investigaciones Científicas, 1952, \$25).

68 Cel, docs. 90 y 110; SantA, docs. 43, 44, 45 y 49.

${ }^{6}$ Cf. García Álvarez, «Sisnando Menéndez, mayordomo real y obispo de Santiago», pp. 226-230; Baliñas Pérez, Defensores e traditores, pp. 64-72; Isla Frez, Amancio. La sociedad gallega en la Alta Edad Media. Madrid: Consejo Superior de Investigaciones Científicas, 1992, pp. 84-89; Ayala Martínez, Sacerdocio y reino en la España altomedieval, pp. 219-220; Portela Silva, «El rey y los obispos», pp. 223-225.

${ }_{70}$ SantA, docs. 46,47 y 48.

71 Sob, doc. 106. 
LOS CONDES DE PRÉSARAS Y LA FUNDACIÓN DE SAN SALVADOR DE SOBRADO. EL INTENTO DE UNA PARENTELA MAGNATICIA POR RECUPERAR SU PREEMINENCIA EN GALLECIA GONZALO ESCUDERO MANZANO

sido encarcelado y que habría perdido la cátedra iriense en detrimento de Rosendo Gutiérrez, el fundador de Celanova ${ }^{72}$. A pesar de que se ha aceptado la veracidad de esta información contenida en fuentes muy posteriores ${ }^{73}$, los testimonios literarios no se corresponden con los diplomáticos, pues las únicas menciones de Rosendo sustituyendo al titular compostelano proceden de sendas escrituras asturicenses falsas ${ }^{74}$; igualmente, la existencia de un prelado homónimo leonés no hace sino enturbiar esta compleja cuestión ${ }^{75}$.

Antonio Palomeque ya intuyó que Sisnando tal vez no fue encarcelado, sino que simplemente se retiró a su monasterio ${ }^{76}$. Si atendemos a la documentación sobradense de estos años ${ }^{77}$, únicamente en uno de los textos se reconoce el gobierno de Sancho I. Se trata de la donación de una villa en Montaos por parte de un presbítero, quien señala con una fórmula un tanto ambigua e inusual que este acto se produjo anno regis Sancti Ramiri prolis et iriense sedis patri domno Sisnando episcopo. Parece ser que, en un nuevo contexto de fragmentación territorial y de debilidad de la monarquía, coexistieron de forma simultánea en Gallecia la autoridad regia de Sancho I y la autoridad episcopal de Sisnando Menéndez, quien — como subrayó Carlos Baliñas - habría perseguido la creación de una «pequeña isla de poder privado» ajena a la intromisión del regnum ${ }^{78}$.

5 CONClusión. LA INVERSIÓN MONÁSTICA COMO UNA FORMA DE POTENCIAR LA ATENCIÓN REGIA Y DE CONSERVAR EL PATRIMONIO

A partir del último tercio del siglo x, la situación al frente de la sede jacobea sufrió cambios significativos. Tras el pontificado de Rosendo Gutiérrez, la Historia Compostelana y el Cronicón Iriense señalan que fue sucedido al frente de esta cátedra por Pelayo, hijo del comes Rodrigo Velázquez ${ }^{79}$. Sin embargo, este prelado en ningún momento aparece en Santiago, al contrario, todas sus acciones registradas proceden del monasterio de Celanova ${ }^{80}$. Por consiguiente, parece que la dignidad iriense cambió de titulares y la recibieron individuos relacionados con la parentela de los Gutiérrez, en detrimento de

72 HC, I, 2, \$6; CI, \$10; Díaz y Díaz, Manuel C., Pardo Gómez, M. a Virtudes y Vilariño Pintos, Daría (eds.). Vida y milagros de San Rosendo. La Coruña: Fundación Pedro Barrié de la Maza, 1990, \$17.

73 García Álvarez, «Sisnando Menéndez, mayordomo real y obispo de Santiago», pp. 227-230; Barreiro Somoza, El señorio de la Iglesia de Santiago de Compostela, pp. 82-83; Ayala Martínez, Sacerdocio y reino en la España altomedieval, pp. 219-220.

74 Ast, docs. 128 y 129. Para la invención de su contenido, vid. Deswarte, Thomas. «Restaurer les évêchés et falsifier la documentation en Espagne. La suppresion du diocèse de Simancas (974) et l'église cathédrale d'Astorga». Revue Mabillon, 2004, vol. 15, pp. 81-106.

75 Carriedo Tejedo, Manuel. «Un obispo desconocido de León. Sisnando II Baroncélliz (año 982)». En Morán Suárez, M. a Antonia y Rodríguez López, M. ${ }^{a}$ Carmen (eds.). La documentación para la investigación. Homenaje a José Antonio Martín Fuertes. León: Universidad de León, 2002, t. I, pp. 129-156.

76 Palomeque Torres, Episcopologio de las sedes del reino de León, pp. 323-329.

77 Sob, docs. 5, 6 8, 45 y 122.

78 Baliñas Pérez, Gallegos del año mil, p. 218.

79 HC, I, 2, \$7; CI, \$12.

80 Cel, docs. 187, 188, 190, 197 y 204. 
LOS CONDES DE PRÉSARAS Y LA FUNDACIÓN DE SAN SALVADOR DE SOBRADO. EL INTENTO

los descendientes del comes Aloito. Entretanto, tras el fallecimiento de Sisnando, Ramiro III consiguió acabar con la insubordinación de este monasterio situando al frente del mismo a un agente afín a los intereses del regnum, el abad Pedro, quien — fruto de esta colaboración - recibió una serie de comitatos que había monopolizado la parentela de Hermenegildo Aloítez ${ }^{81}$.

Con Bermudo II al frente del regnum, la inestabilidad en el noroeste peninsular se frenó levemente y se retornó a una situación similar a la de principios de la centuria. La política del monarca pivotó en las donaciones a Compostela ${ }^{82}$, sede donde fue proclamado rey y el principal baluarte de su autoridad y de su legitimidad ${ }^{83}$. Por su parte, Celanova fue desplazado a una posición secundaria ${ }^{84} \mathrm{y}$, por lo tanto, la coyuntura se invirtió, como podemos observar en el Gráfico 3:

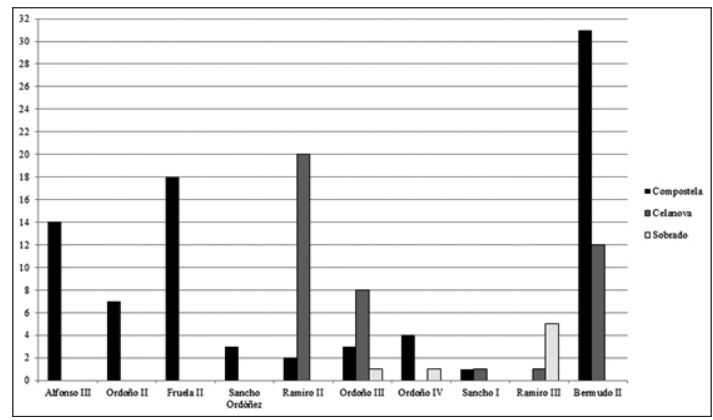

Gráfico 3: Donaciones totales de la monarquía a Compostela, Celanova y Sobrado contenidas en los distintos diplomas regios. Fuente: SantA, docs. 12, 13, 15, 21, 22, 23, 24, 25, 27, 29, 32, 33, 36, 37, 38, 39, 40, 43, 44, 45, 46, 47, 48, 49, 50, 51, 53, 54, 56 y 57; Cel, docs. 47, 69, 85, 90, 110, 197 y 204; Sob, docs. 106 y 107.

A lo largo de estas páginas hemos visto que la construcción de San Salvador de Sobrado a mediados del siglo x por los condes de Présaras fue una reacción de esta parentela ante la pérdida de protagonismo económico en la que se encontraban. Con su fundación, no solo trataron de evitar la disolución de su patrimonio, sino que también fue una forma de atraer el favor de la política de donaciones regias en un espacio en el que nuevos agentes estaban comenzando a captar la atención de la monarquía. No obstante, como señaló M. a del Carmen Pallares, este monasterio experimentó un gran crecimiento siempre que contó con el respaldo de sus fundadores, mientras que a partir de la muerte de los últimos descendientes directos de los Menéndez, esta institución prácticamente desapareción ${ }^{85}$.

81 Sob, doc. 107.

82 SantA, docs. 53, 54, 56 y 57.

83 Isla Frez, Amancio. Realezas hispánicas del año mil. Sada: Ediciós do Castro, 1999, pp. 45-48.

84 Cel, docs. 197 y 204.

85 Pallares Méndez, El monasterio de Sobrado, pp. 76-83. 
LOS CONDES DE PRÉSARAS Y LA FUNDACIÓN DE SAN SALVADOR DE SOBRADO. EL INTENTO DE UNA PARENTELA MAGNATICIA POR RECUPERAR SU PREEMINENCIA EN GALLECIA GONZALO ESCUDERO MANZANO

No sabemos hasta qué punto la crisis sucesoria tras la defunción de Ramiro II y el debilitamiento de la autoridad regia que se extendió durante la segunda mitad de la centuria repercutió negativamente en la inversión de los condes de Présaras. Acaso viendo que su proyecto corría el riesgo de fracasar, decidieron secundar las aspiraciones de Ordoño IV para hacerse con el control del regnum, una nueva estrategia que a corto plazo les reportó beneficios inmediatos. Sin embargo, todas estas apuestas no consiguieron paliar la decadencia de la poderosa parentela responsable de integrar Gallecia en la monarquía ovetense y representante de la autoridad astur-leonesa a nivel local desde la cátedra compostelana. Tras su esplendor durante las primeras décadas del siglo x, los descendientes del comes Aloito desaparecieron del escenario magnaticio altomedieval hispánico a finales de la misma centuria.

\section{REFERENCIAS BIBLIOGRÁFICAS}

Amaral, Luís C. (ed.). Livro de Mumadona. Cartulário do mosteiro de Guimarães. Edição crítica. Lisboa: Academiae Scientarum Olisiponensis, 2016.

Ayala Martínez, Carlos de. Sacerdocio y reino en la España altomedieval. Iglesia y poder político en el occidente peninsular, siglos VII-XII. Madrid: Sílex, 2008.

Baliñas Pérez, Carlos. «Igrexa e política na Galicia do periodo asturiano (718-910)». Cuadernos de Estudios Gallegos, 1986, vol. 36, pp. 69-87.

Baliñas Pérez, Carlos. Defensores e traditores. Un modelo de relación entre poder monárquico e oligarquia na Galicia altomedieval (718-1037). Santiago de Compostela: Xunta de Galicia, 1988.

Baliñas Pérez, Carlos. Do mito á realidade. A definición social e territorial de Galicia na Alta Idade Media (séculos VIII e IX). Santiago de Compostela: Fundación Universitaria de Cultura, 1992.

Baliñas Pérez, Carlos. Gallegos del año mil. La Coruña: Fundación Pedro Barrié de la Maza, 1998. Barreiro Somoza, José. El señorio de la Iglesia de Santiago de Compostela (siglos IX-XIII). La Coruña: Diputación Provincial de La Coruña, 1987.

Branco, M.a João. «Portugal no reino de León. Etapas de uma relação (866-1179)». En El reino de León en la Alta Edad Media. vol. IV. León: Centro de Estudios e Investigación San Isidoro, 1993, pp. 533-625.

Carriedo Tejedo, Manuel. «Un obispo desconocido de León. Sisnando II Baroncélliz (año 982)». En Morán Suárez, M. ${ }^{\mathrm{a}}$ Antonia y Rodríguez López, M. ${ }^{\mathrm{a}}$ Carmen (eds.). La documentación para la investigación. Homenaje a José Antonio Martín Fuertes. León: Universidad de León, 2002, t. I, pp. 129-156.

Carvajal Castro, Álvaro. Bajo la máscara del regnum. La monarquía asturleonesa en León (8541037). Madrid: Consejo Superior de Investigaciones Científicas, 2017.

Carvajal Castro, Álvaro y Martín Viso, Iñaki. «Historias regionales de la repoblación. Los reyes asturleoneses y las "políticas de la tierra" en el oeste de la Meseta del Duero». En Díaz Martínez, Pablo C., Luis Corral, Fernando y Martín Viso, Iñaki (coords.). El historiador y la sociedad. Homenaje al profesor José Ma Minguez. Salamanca: Universidad de Salamanca, 2013, pp. 39-52.

Castellanos García, Santiago y Martín Viso, Iñaki. «The local articulation of central power in the North of the Iberian Peninsula (500-1000)». Early Medieval Europe, 2005, vol. 13, pp. 1-42. 
LOS CONDES DE PRÉSARAS Y LA FUNDACIÓN DE SAN SALVADOR DE SOBRADO. EL INTENTO

Cavero Domínguez, Gregoria y Martín López, Encarnación (eds.). Colección documental de la catedral de Astorga. Vol. I (646-1126). León: Centro de Estudios e Investigación San Isidoro, 2000.

«Chronicon Laurbanense». En Portugaliae Monumenta Historica. Scriptores. Lisboa: Academiae Scientarum Olisiponensis, 1856, vol. I, p. 20.

«Crónica Albeldense». En Gil Fernández, Juan, Moralejo Álvarez, José Luis y Ruiz de la Peña, José Ignacio (eds.). Crónicas asturianas. Crónica de Alfonso III (Rotense y "a Sebastián»). Crónica Albeldense ( $y$ "Profética»). Oviedo: Universidad de Oviedo, 1985.

Dacosta Martínez, Arsenio. «Pelayo vive! Un arquetipo político en el horizonte ideológico del reino asturleonés». Espacio, Tiempo y Forma. Serie III, Historia Medieval, 1997, vol. 10, pp. 89-135.

Deswarte, Thomas. De la destruction à la restauration. L'idéologie du royaume d'Oviedo-Léon (VIII'-XI siècles). Turnhout: Brepols, 2003.

Deswarte, Thomas. «Restaurer les évêchés et falsifier la documentation en Espagne. La suppresion du diocèse de Simancas (974) et l'église cathédrale d'Astorga». Revue Mabillon, 2004, vol. 15, pp. 81-106.

Díaz y Díaz, Manuel C., Pardo Gómez, M. a Virtudes y Vilariño Pintos, Daría (eds.). Vida y milagros de San Rosendo. La Coruña: Fundación Pedro Barrié de la Maza, 1990.

Domínguez Sánchez, Santiago (ed.). Colección documental medieval de los monasterios de San Claudio de León, monasterios de Vega y San Pedro de las Dueñas. León: Centro de Estudios e Investigación San Isidoro, 2001.

Earle, Timothy K. How chiefs come to power. The political economy in Prehistory. Stanford: Stanford University Press, 1997.

Escalona Monge, Julio. «Family memories. Inventing Alfonso I of Asturias». En Alfonso Antón, M. a Isabel, Kennedy, Hugh y Escalona Monge, Julio (eds.). Building legitimacy. Political discourses and forms of legitimacy in Medieval societies. Leiden-Boston: Brill, 2004, pp. 223-262.

Escalona Monge, Julio. "In the name of a distant King. Representing royal authority in the County of Castile, c. 900-1038». Early Medieval Europe, 2016, vol. 24, pp. 74-102.

Escudero Manzano, Gonzalo J. «Los escenarios episcopales en el norte hispánico entre la caída del reino visigodo y la configuración del poder leonés (siglos viII-X)». En Díaz-Plaza Casal, Adrián, Escudero Manzano, Gonzalo J. y Villarroel González, Óscar (coords.). Caída y ascenso de las estructuras de poder en la Alta Edad Media. Madrid: La Ergástula, 2020, pp. 79-91.

Falqué Rey, Emma (ed.). Historia Compostellana. Turnhout: Brepols, 1988.

Floriano Cumbreño, Antonio C. (ed.). Diplomática española del período astur. vol. I (desde Pelayo a Ordoño I). Diputación Provincial de Oviedo, Oviedo: Instituto de Estudios Asturianos, 1949.

García Álvarez, Manuel R. (ed.). «El Cronicón Iriense. Estudio preliminar, edición crítica y notas históricas». En Memorial histórico español. Colección de documentos, opúsculos y antigüedades que publica la Real Academia de la Historia. Madrid: Real Academia de la Historia, 1963, pp. 101-121.

García Álvarez, Manuel R. «Sisnando Menéndez, mayordomo real y obispo de Santiago». Compostellanum, 1968, vol. 13, pp. 199-239.

García de Cortázar, José Ángel. «Del Cantábrico al Duero». En García de Cortázar, José Ángel et al. (eds.). Organización social del espacio en la España medieval. La Corona de Castilla en los siglos VIII a XV. Barcelona: Ariel, 1985, pp. 43-83.

Isla Frez, Amancio. "Consideraciones sobre la monarquía astur». Hispania, 1995, vol. 55, pp. 151-168. 
Isla Frez, Amancio. La sociedad gallega en la Alta Edad Media. Madrid: Consejo Superior de Investigaciones Científicas, 1992.

Isla Frez, Amancio. Realezas hispánicas del año mil. Sada: Ediciós do Castro, 1999.

Isla Frez, Amancio. Ejército, sociedad y política en la Península Ibérica entre los siglos VII y XI. Ministerio de Defensa, Madrid: Consejo Superior de Investigaciones Científicas, 2010.

Isla Frez, Amancio. "The aristocracy and the monarchy in Northwest Iberia between the Eighth and the Eleventh century». En D'Emilio, James (ed.). Culture and Society in Medieval Galicia: A Cultural Crossroads at the Edge of Europe. Leiden-Boston: Brill, 2015, pp. 251-280.

López Alsina, Fernando. La ciudad de Santiago de Compostela en la Alta Edad Media. Santiago de Compostela: Universidade de Santiago de Compostela, 1992.

López Alsina, Fernando. "Cabeza de oro refulgente de España”. Los orígenes del patrocinio jacobeo sobre el reino astur». En Ruiz de la Peña, Juan Ignacio (ed.). Las peregrinaciones a Santiago de Compostela y San Salvador de Oviedo en la Edad Media. Actas del Congreso Internacional celebrado en Oviedo del 3 al 7 de diciembre de 1990. Oviedo: Principado de Asturias, 1993, pp. 27-36.

López Ferreiro, Antonio. Historia de la Santa A. M. Iglesia de Santiago de Compostela. Vol. II. Santiago de Compostela: Seminario Conciliar Central, 1899.

Loscertales de Valdeavellano, Pilar (ed.). Tumbos del monasterio de Sobrado de los Monjes. Vol. I. Madrid: Archivo Histórico Nacional, 1976.

Lucas Álvarez, Manuel (ed.). Tumbo A de la catedral de Santiago. Sada: Ediciós do Castro, 1998.

Martín Viso, Ińaki. "Colapso político y sociedades locales. El noroeste de la Península Ibérica (siglos viII-IX)». Reti Medievali Rivista, 2016, vol. 17, pp. 335-369.

Mínguez Fernández, José M.a (ed.). Colección diplomática del monasterio de Sahagún. Vol. I (siglos IX y X). León: Centro de Estudios e Investigación San Isidoro, 1976.

Mínguez Fernández, José M. ${ }^{a}$. «Ruptura social e implantación del feudalismo en el noroeste peninsular (siglos viII-X)». Studia Historica. Historia Medieval, 1985, vol. 3, pp. 7-32.

Mínguez Fernández, José M.a . La España de los siglos VI al XIII. Guerra, expansión y transformaciones. En busca de una frágil unidad. San Sebastián: Nerea, 2004.

Mínguez Fernández, José M.a. «Pervivencia y transformaciones de la concepción y práctica del poder en el reino de León (siglos x y xi)». Studia Historica. Historia Medieval, 2007, vol. 25, pp. 15-65.

Mínguez Fernández, José M. ${ }^{\mathrm{a}}$. «Regnum asturum. Orígenes y primera conformación». Intus-Legere Historia, 2014, vol. 8, pp. 51-69.

Nascimento, Aires A. y Fernández Catón, José M. a (eds.). Liber testamentorum coenobii laurbanensis. León: Centro de Estudios e Investigación San Isidoro, 2008.

Núñez Rodríguez, Manuel. «Inscripciones de la Galicia altomedieval». Revista de Guimarães, 1979, vol. 89, pp. 293-320.

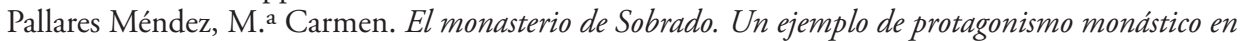
la Galicia medieval. La Coruña: Diputación Provincial de La Coruña, 1979.

Pallares Méndez, M. ${ }^{a}$ Carmen, Ilduara, una aristócrata del siglo X. Sada: Ediciós do Castro, 1998

Palomeque Torres, Antonio. Episcopologio de las sedes del Reino de León. León: Centro de Estudios e Investigación San Isidoro, 1966.

Pérez de Urbel, Justo (ed.). Crónica de Sampiro. Versión Silense. Madrid: Consejo Superior de Investigaciones Científicas, 1952.

Portass, Robert. «All quiet on the Western front? Royal politics in Galicia from c. 800 to c. 950 ». Early Medieval Europe, 2013, vol. 21, pp. 283-306. 
LOS CONDES DE PRÉSARAS Y LA FUNDACIÓN DE SAN SALVADOR DE SOBRADO. EL INTENTO

Portela Silva, Ermelindo. «El rey y los obispos. Poderes locales en el espacio galaico durante el periodo astur». En Fernández Conde, Francisco Javier y García de Castro Valdés, César (coords.). Symposium Internacional Poder y Simbología en Europa, siglos VIII-X. Actas del Symposium Internacional convocado en Oviedo, 22-27 de septiembre del 2008. Oviedo: Trea, 2009, pp. 215-226.

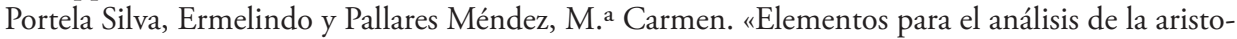
cracia altomedieval de Galicia. Parentesco y patrimonio». Studia Historica. Historia Medieval, 1987, vol. 5, pp. 17-32.

Quirós Castillo, Juan Antonio y Santos Salazar, Igor. «Territorios sin ciudades y complejidad social. El Cantábrico oriental en la Alta Edad Media». En Sabaté i Curull, Flocel y Brufal Sucarrat, Jesús (eds.). La ciutat medieval i Arqueologia. VI Curs Internacional d'Arqueologia Medieval. Lleida: Pagès, 2014, pp. 139-174.

Reglero de la Fuente, Carlos (ed.). El monasterio de San Isidro de Dueñas en la Edad Media. Un priorato cluniacense hispano (911-1478). Estudio y colección documental. León: Centro de Estudios e Investigación San Isidoro, 2005.

Rodríguez Fernández, Justiniano. «La monarquía leonesa. De García I a Vermudo III». En El reino de León en la Alta Edad Media. Vol. III. León: Centro de Estudios e Investigación San Isidoro, 1995, pp. 131-413.

Rodríguez González, Ángel (ed.). El tumbo del monasterio de San Martín de Castañeda. León: Centro de Estudios e Investigación San Isidoro, 1973.

Sáez Sánchez, Emilio. "Ramiro II, rey de "Portugal”». Revista Portuguesa de História, 1947, vol. 3, pp. 271-290.

Sáez Sánchez, Emilio. «Los ascendientes de san Rosendo. Notas para el estudio de la monarquía astur-leonesa durante los siglos IX y X». Hispania, 1948, vol. 8, pp. 5-136.

Sáez Sánchez, Emilio (ed.). Colección documental del archivo de la catedral de León (775-1230). Vol. I (775-952). León: Centro de Estudios e Investigación San Isidoro, 1987.

Sáez Sánchez, Emilio y Sáez Sánchez, Carlos (eds.). Colección diplomática del monasterio de Celanova (842-1230). Alcalá de Henares: Universidad de Alcalá de Henares, 1996-2006, 3 vols.

Sánchez Pardo, José Carlos. «Power and rural landscapes in Early Medieval Galicia (400-900 AD). Towards a re-incorporation of the Archaeology into the historical narrative». Early Medieval Europe, 2013, vol. 21, pp. 140-168.

Torres Sevilla-Quiñones de León, Margarita. Linajes nobiliarios en León y Castilla (siglos IX-XIII). Valladolid: Junta de Castilla y León, 1999.

Viguera Molins, M. ${ }^{a}$ Jesús, Corriente Córdoba, Federico y Lacarra de Miguel, José M.a (eds.). Crónica del califa 'Abderramān III an-Näsir entre los años 912 y 942 (al-Muqtabis V). Zaragoza: Anubar, 1981. 